\title{
Modelling of real-world problems is often the starting point for proof
}

\author{
Vimolan Mudaly \\ Department of Mathematics Education, University of KwaZulu-Natal, South Africa \\ Email:vims@mweb.co.za
}

In this paper I claim that modelling should be seen as the first stage of the proving process. I discuss an experiment conducted with grade 10 (15 year old) learners in a small suburb in South Africa. There is little emphasis placed on modelling in our schools and it is just beginning to make an appearance in our new Outcomes Based Curriculum. The research shows that as a result of the modelling process learners felt the need to know why the result was true. There is ample evidence that a lot of work on a similar topic has been done elsewhere in the world, but not much has been done in South Africa. The research was conducted using Sketchpad as a mediating tool. This in itself was a difficult task because our learners have not really been exposed to dynamic geometry environments.

\section{Introduction}

Proof is often only seen as a means of simply verifying the truth of mathematical statements. Although proof should be seen as serving many functions, it would seem that establishing certainty in a statement has been its main function. According to Davis and Hersh (1981: 249) this can be traced back to the Greek mathematicians who saw the proof process as that of validation and certification. A survey conducted in 1984 by De Villiers (1999: 18) revealed that more than $50 \%$ of Higher Education Diploma students in mathematics education agreed that the only function of proof was that of "making sure", that is, the verification of the truth of the results.

This is a perception that is commonly propagated in mathematics classrooms, where teachers focus on the verifying of mathematical truths that are being investigated. Seldom is there a link established between mathematical modelling of real-world problems and proving. This is also the finding of Hodgson and Riley (2001: 724), who state that that "proof and real-world problemsolving are typically considered to be separate and distinct endeavours". It has always been difficult to gauge the relationship between real-world problem-solving and proof, yet the clear value of real-world problem-solving in the process of proving cannot be underestimated. that:

Hodgson and Riley (2001: 724) further state

our experience has been that real-world problems supply an important ingredient that seems to be missing from typical classroom instruction on proof. As such, real-world problems may actually be one of the most effective contexts for introducing and eliciting proof. Realworld problems are commonly used as vehicles to introduce or deepen students' understanding of mathematical concepts and relationships.

Hodgson and Riley's argument that real-world problems could be the basis for mathematical proof stems from one step in the modelling process, namely, the testing of the solution. They believe that it is essential for students to ask "why is the statement true?" after they have arrived at a solution. In their experiment the students found that their solution was incorrect and this initiated the desire for an explanation. It is my contention that had they not gone through the process of modelling, it is unlikely that they would have wanted an explanation.

Similarly, Klaoudatos and Papastavridis (2001) discuss a teaching experiment based on Context Oriented Teaching (COT). According to Klaoudatos and Papastavridis, COT is "a model based on a problem solving framework and on the selection of the appropriate task context" (p. 1). They observe that COT provides the student who has little understanding of the mathematics involved in solving a particular problem, with a starting point and a sense of direction. Essentially, they conclude that starting with a Context Oriented Question (which is an adapted real-world question), the learners use Context Oriented Heuristics to develop Context Oriented Concepts. Context Oriented Conjectures are formulated, which leads to Context Oriented Proofs. Despite framing their arguments within the idea of 
contexts, they still show that the modelling activity serves as a starting point for this proof.

A further significant argument which shows this direct link between modelling and proof is made by Blum (1998) when he states that applications in mathematics (solving of real-world problems) provide contexts for what he refers to as reality-related proofs. He clearly points out that:

formal proofs are mostly the final stage in a genetic development - historically as well as epistemologically as well as psychologically. (p. 4)

However, Klaoudatos and Papastavridis (2001) as well as Blum (1998) discuss proving in relation to modelling in teaching situations which have been explicitly designed so as to connect the two. The question still remains whether the modelling activity will still serve as a starting point for proof if the specific modelling activity is not constructed with the intention of arriving at a proof. Furthermore, it is relevant to ask whether the experiences gained from the European contexts will be similar in South African classrooms, with different traditions, and teacher-learner relationships and numbers. I address both these questions below.

\section{Real-world problems}

The direct connection between classroom mathematics and real-world mathematics is a tenuous one, because it is often difficult to relate classroom mathematics to what happens in the real world. If the word "real" in this instance is not only interpreted as a connection to the real world, but as a reference to the problem situations which appear to be real in the learner's mind, then the relationship between real-world and classroom mathematics becomes a bearable one. Furthermore, if mathematics is to be related to reality, not only is reference being made to real-world problems but also to the fact that the mathematics must make sense to children. It must remain as close as possible to the concepts that children already have and know. The work they do must appeal to them within the frames of reference that they understand. Selden and Selden (1999) state that:

from the perspective of Realistic Mathematics Education, students learn mathematics by mathematizing the subject matter through examining 'realistic' situations, i.e., experientially real contexts for students that draw on their current mathematical understandings. (p. 9)
Clearly, the problem presented precedes the abstract mathematics that is to be learned.

According to Van den Heuvel-Panhuizen (1998):

The reason ... why the Dutch reform of mathematics education was called 'realistic' is not just the connection with the real-world, but is related to the emphasis that RME [Realistic Mathematics Education] puts on offering the students problem situations which they can imagine. (p. 1)

The Realistic Mathematics educators place immense emphasis on the idea of making a mathematical idea real in the mind of the learner.

So when working with real-world problems the learner should first be exposed to a problem situation that they are familiar with and it must appear to be real. This then allows them to use their previous experiences to interact and engage with the problem at hand. It is this interaction with a familiar situation that leads to the development of a predetermined mathematical concept. Through further interrogation of the problem situation and its results the learner develops a better understanding of the concept (Zulkardi, 2003: 6).

Although it may be difficult to replicate realworld conditions in a mathematics classroom, it is essential to expose learners to different real-world scenarios so that they learn mathematics in contexts that are familiar to them. Bonotto (2004) states that:

progressive mathematization should lead to algorithms, concepts and notations that are rooted in a learning history which starts with students' informal experientially real knowledge. In our approach everyday-life experience and formal mathematics, despite their specific differences, are not seen as two disjunctive and independent entities. Instead, a process of gradual growth is aimed for, in which formal mathematics comes to the fore as a natural extension of the students' experiential reality. (p. 42)

Besides the ideal of showing learners how mathematics is related to the real world it also serves to increase interest in the subject matter. Bowman (1997: 8) states that after allowing his students to work with real-world problems in his class the level of student interest increased to the extent that "they were especially excited about being able to solve a mathematics problem that even the so-called 'math geniuses' in calculus could not solve". 


\section{The process of modelling and its relationship to proving}

In order to understand the relationship between proof and modelling, one needs to have some knowledge of the processes involved in modelling. Modelling is not an easy task. It often involves a process of creating a miniature problem, which is analogous to the larger problem, but enables the modeller to draw exact conclusions, which can be extrapolated to the original real-life problem. Although a model attempts to simulate the original problem it cannot truly replicate all the constraints that might be imposed by the problem itself.

Modelling usually begins with a real-life situation which may be relatively controlled (for example, determining the profit of a manufacturing company), or sometimes in environments in which the modeller cannot control all the conditions (for example determining the population increase of fish in a river). In all cases the modeller is hoping to predict future behaviour of the system under prevailing conditions.

This research was based on the following diagrammatic explanation of the modelling process of Michael Olnick (1978:4). Refer to Figure 1.
In evaluating a model and its results the modeller begins to ask why does the result hold true? (or even why does the result not hold true?). It is this question that clearly defines the relationship between modelling and proving.

Asking why indicates a desire to seek some sort of explanation. It is also clear that the question is not whether the result is true because the modeller has already convinced him/herself that the result is true during the interpretative stage. Once convinced the modeller develops a certain curiosity as to why the result is true and possible under such conditions. In attempting to answer this question the modeller begins to develop an explanation for the observed result and hence establishes a proof valuable in increasing the understanding of the problem.

\section{The purpose of this study and the theoretical framework}

The purpose of this study was to determine whether Sketchpad could be useful as a mathematical tool when teaching children to model. Furthermore, this study tested curriculum material that was developed (De Villiers, 1999)

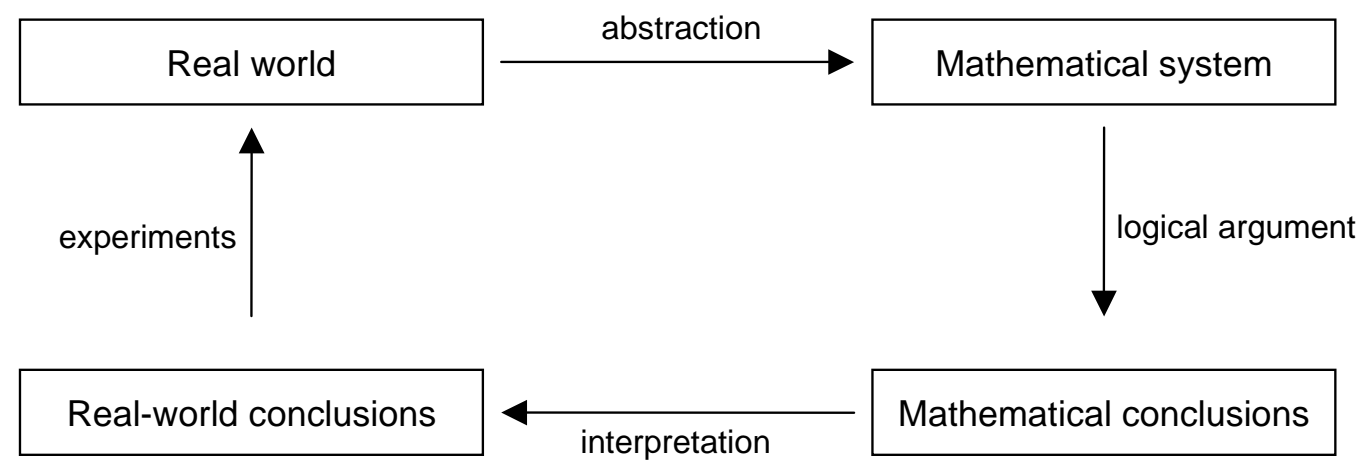

Figure 1. Diagrammatic representation of Olnick's modelling process

The model depicted in Figure 1 was adapted to include other technologies in the modelling process. For the purposes of this research the technology used was the computer software package Sketchpad. Refer to Figure 2.

De Villiers (1993: 3) describes three different categories of model application namely, direct application ('immediate recognition of a model to be used'), analogical application ('development of a model that is similar to an existing model'), and creative application ('a completely new model is created using new techniques and concepts'). The experiment described below is entrenched in the creative application. and refined as a result of previous empirical and theoretical research. The material in the form of worksheets allowed the learner to work through the problem by guiding the child through stages that are easy and practical. As the child progressed through the worksheets, the child was allowed to record his/her conclusions and conjectures and this led to an explanation (proof).

The theoretical and empirical part of this research focused on the following major research questions:

1. What is the role and function of mathematical modelling in mathematical sciences, and its potential role in mathematics education? 


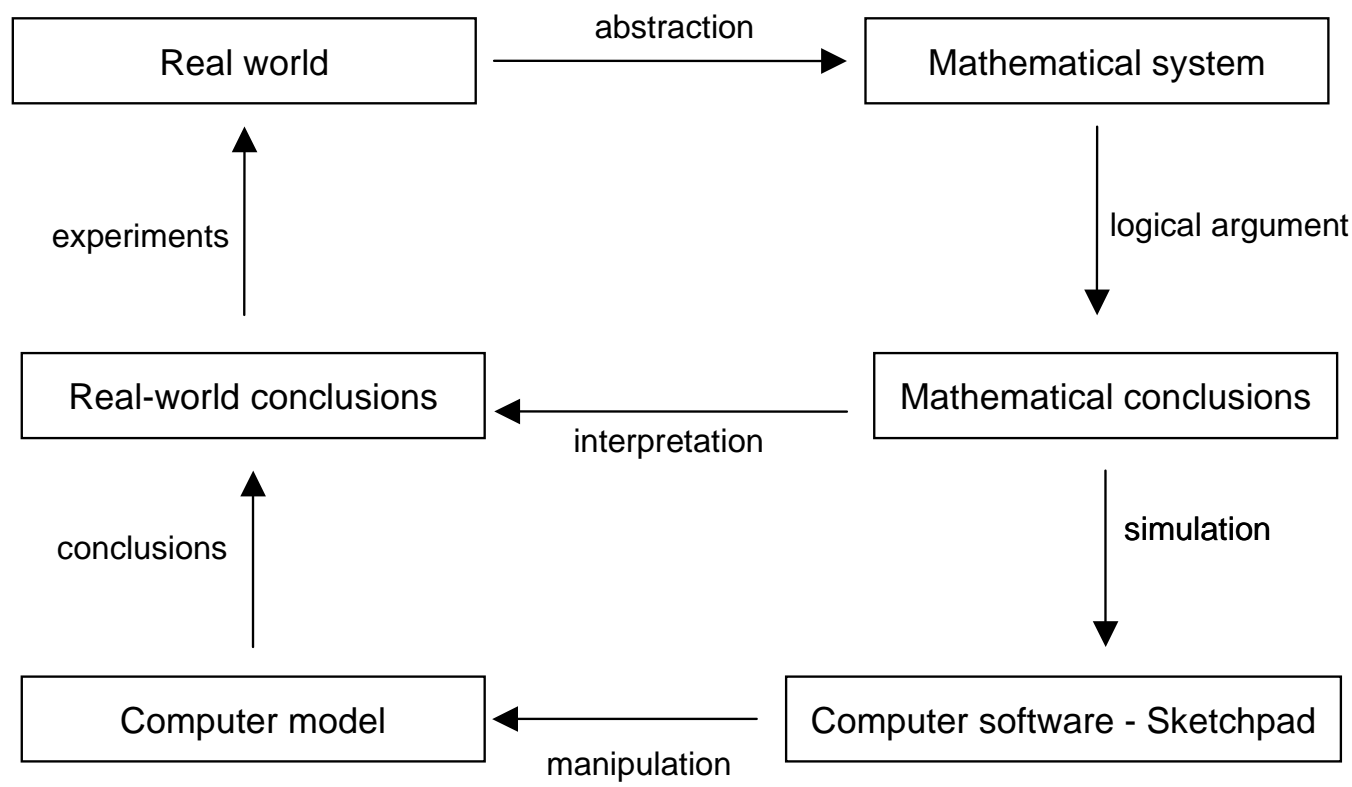

Figure 2. Sketchpad modelling process

2. Can learners acquire knowledge about geometric concepts and shapes such as equidistance, perpendicular bisectors and concurrency via creative modelling?

3. Are secondary school learners able to create and use mathematical models to solve geometric problems in the real world without the use of Sketchpad? If so, what strategies do they use?

4. Are learners able to use the provided Sketchpad sketches effectively to arrive at reasonable solutions?

5. Do learners display greater understanding of the real-world problems under question when using Sketchpad?

My one-to-one task-based interviews were analysed using qualitative methods. This method made it easier to document the high level of information that individual children display when working through a specific problem. Furthermore, this method allowed the researcher greater control to observe and take note of how each learner answered questions based on the computer manipulation they experienced.

The tasks used in the interviews had been conceptualised within an action research paradigm. These tasks were conceptualised mainly as a means of teaching children the different functions of proof developed by de Villiers (1999), and also included aspects of modelling. This research attempted to determine how well they coped with the tasks provided, whether they construct meanings as conceptualised, and whether they would be able to mathematically model a solution. Based on initial trials the tasks had to be redesigned in order to achieve the predetermined goals of the learning activity. In other words, action research acted as a guiding methodology.

The task that the learners had to work through was based on a relevant real-world topic. All learners were exposed to the different media in South Africa and from prior questioning it was established that all learners were aware of the seriousness of the water born illness called cholera. Learners were also aware that cholera was mainly concentrated in rural areas, particularly in areas where no fresh water was available. Hence, identification with the problem was not new and difficult.

All the Sketchpad sketches were presented as ready-made models to the learners. The task of constructing such models is also an essential modelling skill and would be an interesting task to ask of learners. For example, it would require them choosing and implementing a reasonable scale and utilising Sketchpad's tools to accurately construct a dynamic scale drawing. The decision to present the sketches directly to them was based on the following reasons:

- The construction of accurate, dynamic Sketchpad sketches requires a fairly high level of technical expertise.

- Even if learners had had a sufficiently high level of expertise, it would have been very time 
consuming to construct the sketches.

- The research was aimed at ascertaining whether learners could use these given Sketchpad sketches effectively to solve real-world problems, and not on their ability to construct such sketches themselves.

- Moreover, the research was aimed at investigating whether learners could, through using these given sketches, acquire understanding of important concepts such as bisector, circumcentre, circum-circle, cyclic quadrilateral, and some properties of these.

All of the activities were entrenched in the constructivist belief that "the learners have their own ideas, that these persist despite teaching and that they develop in a way characteristic of the person and the way they experience things, leads inevitably to the idea that, in learning, people construct their own meaning" (Brookes, 1994: 12). There is little doubt that children enter mathematics classes with views and ideas of certain mathematical occurrences that they experience in real life. They, for example, may be aware that water reservoirs are generally constructed at the top of the highest hill in a village because the pressure required to feed the water to large distances must be great. They may be aware that in order to establish the height of a mountain, it is basically impossible to start from the top of the mountain with a tape measure and work downwards towards the foot of the mountain. They may not know how the height is calculated, but they could have a sense that mathematics would play a role. Often, mathematics educators make the flawed assumption that learners are empty vessels into which knowledge must be poured. The constructivist view is completely opposite and is based on the theory that learning is an active process and that learners construct their own meaning. This therefore implies that learners themselves are responsible for their own learning.

Closely linked to this socio-constructivist theory is the Problem-Centred Learning (PCL) approach, developed in South Africa in the mid 1980 s by researchers at the University of Stellenbosch. The PCL approach is based on a socio-constructivist theory of the nature of knowledge and learning and hinges on the following (Olivier, Murray and Human, 1992: 33):

- The learner is active in the process of acquiring knowledge.

- In acquiring this knowledge, the learner makes use of past experiences and existing knowledge.
- Learning is a social process and the learner acquires new knowledge through interaction with other learners and educators.

Research conducted by the Research Unit for

Mathematics Education at the University of

Stellenbosch (Olivier, Murray and Human, 1992)

showed that the:

majority of children invent powerful nonstandard algorithms alongside schooltaught standard algorithms; that they prefer to use their own algorithms when allowed to do so and that their success rate when using their own algorithms is significantly higher than the success rate of children who use the standard algorithms or when they themselves use standard algorithms. (p. 33)

This research clearly contributed to the general constructivist theory of children creating their own knowledge from their own experiences and not from the experiences of the educator or textbook author.

\section{The research itself}

In a modelling experiment conducted with grade 10 learners to teach concepts such as perpendicular bisectors and concurrency, it was found that these learners displayed a definite desire for a proof. I initially envisaged that it would not be necessary to develop and pursue the actual proof of their discovery, because the aim of the investigation simply was to determine whether Sketchpad could be used as a modelling tool in developing new concepts (such as concurrency and perpendicular bisectors). Later, I felt that it was useful and necessary to investigate whether learners could actually be guided to a simple proof based on their modelling activity. The proof was based on materials developed by De Villiers (1999: 32).

A real-world problem was given to the students, contextualised within the South African rural background. The question was:

In a developing country like South Africa, there are many remote villages where people do not have access to safe, clean water and are dependent on nearby streams or rivers for their water supply. With the recent outbreak of cholera in these areas, untreated water from these streams and rivers has become dangerous for human consumption. Suppose you were asked to determine the site for a water reservoir and purification plant so that it would be the same distance away from four remote villages. 
Where would you recommend the building of this plant?

The students were presented with already constructed diagrams using Sketchpad as a mediating tool. The diagrams were constructed in a way that allowed the students to eventually model a solution to the above question. After the students had gone through the process of working on a dynamic quadrilateral and discovering that only the perpendicular bisectors of a cyclic quadrilateral were concurrent, they were asked a similar question related to three villages. They readily conjectured that perpendicular bisectors would be concurrent for only those triangles that were cyclic. They were enormously surprised when they used the drag function of Sketchpad to discover that the perpendicular bisectors of all triangles were concurrent.

When asked if they wanted to know why this is true all students gave the impression that they wanted an explanation in order to extract some understanding from it. The proof was not required because they doubted the result but only because they felt that it would satisfy some innate curiosity around the reason for the result.

\section{An example of a learner's proving process and strength of conviction}

Only one example of the proving process is cited to convey the gist of what transpired after the learners felt the need for an explanation.

TEACHER Look at this triangle on the screen again. Construct the perpendicular bisector of any side.

DESIGAN Can I do it for AB?

TEACHER Yes. (after the construction) Desigan, what can you tell me about all the points on this perpendicular bisector?

DESIGAN It is equidistant from A and B.

TEACHER What is equidistant? (trying to ascertain for sure what the 'it' was)

DESIGAN All the points on this line (pointing to the perpendicular bisector).

TEACHER What does that really mean to you?

DESIGAN If you measure the distance from any point on this line to this $\mathrm{A}$ and $\mathrm{B}$, the distance will be the same.

In this segment I was simply attempting to get the learner to recall the concepts of perpendicular bisector and equidistant. In a way, it was also a means of determining whether the learner actually understood and remembered what he had done earlier in the interview.

TEACHER Now construct any other perpendicular bisector.

DESIGAN (constructing)

TEACHER What can you tell about the points on this line now?

DESIGAN All the points are the same distance away from $B$ and $C$.

TEACHER Now look at this point of intersection. What can you say about this point in particular?

DESIGAN Eh ... eh...

TEACHER Think carefully about the point.

DESIGAN That point there is the same distance away from $\mathrm{A}$ and $\mathrm{B}$ and, $\mathrm{B}$ and $\mathrm{C}$.

TEACHER $\mathrm{A}$ and $\mathrm{B}$ and, $\mathrm{B}$ and $\mathrm{C}$ ?

DESIGAN Yes, it is the same distance away from $\mathrm{A}, \mathrm{B}$ and $\mathrm{C}$.

TEACHER Are you sure?

DESIGAN It lies on this line so it must be equidistant from $\mathrm{A}$ and $\mathrm{B}$ and it lies on that line so it must be equidistant from $\mathrm{A}$ and $\mathrm{C}$ (note the error).

TEACHER If it lies on that line would it be equidistant from $\mathrm{A}$ and $\mathrm{C}$ ?

DESIGAN No B and C.

TEACHER So are you sure that this point of intersection is the same distance away from $\mathrm{A}, \mathrm{B}$ and $\mathrm{C}$ ?

DESIGAN Yes.

Initially, it seemed that this learner realised that the point of intersection was equidistant in a fragmented way. In other words, he could see that the point of intersection was equidistant from $\mathrm{A}$ and $\mathrm{B}$ and $\mathrm{B}$ and $\mathrm{C}$ separately. He did not instantaneously see the connection between all of the vertices to the point of intersection.

TEACHER You have to think about this very carefully. What can you say about the perpendicular bisector of AC?

DESIGAN All the points will be equidistant from $\mathrm{A}$ and $\mathrm{C}$.

TEACHER Yes, that is correct. But look at the other perpendicular bisectors.

DESIGAN (silence for a while) ....Oh yes, it must pass through the point where these two lines meet (pointing to the perpendicular bisectors).

TEACHER Really?

DESIGAN Yes because if all the points on this perpendicular bisector of $\mathrm{AC}$ are the 
same distances away...then ... then this point of intersection is also the same distance away .. then...

TEACHER Yes?

DESIGAN Then the line must pass through the point of intersection.

TEACHER Are you absolutely sure that this would happen?

DESIGAN Yes, I'm positive.

TEACHER Do you want to see whether that is true?

DESIGAN Yes.

TEACHER Construct the perpendicular bisector of $\mathrm{AC}$ then.

DESIGAN (after constructing) This is so easy.

TEACHER Was it really that easy?

DESIGAN I didn't take so long to get it right!

Eventually, when he realised that there was a connection between the three vertices and the point of intersection, the rest of the explanation became simple. It was clear that because these learners had initially worked in the modelling process, with the concept of equidistance, the actual proof became easy to understand. This is supported by the fact that the learner felt that this explanation was quite easy, and, furthermore, he felt that he alone had got it correct. This must be attributed to the high level of conviction that could be achieved using Sketchpad as a mediating tool.

It must also be pointed out that during the modelling process itself the learner was encouraged to find the link between the real-world situation and the modelling activity itself. When the learners were asked what this result meant in terms of the three villages, some of the responses were as follows:

DESIGAN You can join the three villages and then find the perpendicular bisectors. Where they meet is the important point for us to use.

TEACHER Do you think that it is easy to just join these villages and find the perpendicular bisectors?

DESIGAN I don't think that it's easy ... I'm sure they can draw it on a page first and then do an exact drawing ... or even use this programme to get the exact position.

TEACHER Do you think that this would be easy to do in real life?

DESIGAN I don't know... we must consider a lot of factors ... like we discussed in the beginning.
VISCHALAN If the villages are situated like this triangle then all you have to do is join the villages, find the midpoints between them and construct the perpendicular bisectors. The point of concurrency will be the most suitable point.

TEACHER Do you think that it is easy to just join these villages and find the perpendicular bisectors?

VISCHALAN Yes ... you can use a map of the area.

TEACHER Do you think that this would be easy to do in real life?

VISCHALAN My uncle told me that you can use GPS (Global Positioning System) to find any point you want. I think the government has pictures of every part of the country.

It was evident from some of their responses that these learners were quite capable of transposing real-world problems into mathematical systems and returning to the real world as they see it.

\section{Conclusion}

Within the context of teaching a real-world problem, the evidence presented by the learners involved in this study, indicates that there is some reason to believe that using modelling situations in a classroom may lead to mathematical proving opportunities. Although it cannot be conclusively stated that all modelling activities will lead to the proving process, this experiment does reveal that given certain modelling opportunities, learners may, as a result of the high levels of conviction established, want an explanation for the results they observe. The researcher also concedes that in the pseudo-real-world problem that the learners had to solve, the inductive process was made easier by the use of Sketchpad, and indeed the deductive process was also catalysed by what the learners could see whilst working with Sketchpad. But it is the contention of the researcher that it is exactly this combination which facilitated a level of understanding not easily achieved by ordinary pencil and paper methods. As a result of this high level of understanding, which began with the modelling process, the learners felt a need for an explanation (proof). 


\section{References}

BLUM, W., 1998, "On the Role of "Grundvorstellungen' for Reality-Related Proofs Examples and Reflections", in Gailbraith P. et al., Mathematical Modelling - Teaching and Assessment in a Technology -Rich World. Retrieved October 13, 2003 from URL http://www.lettredelapreuve.it/CERME3Papers/ TG4-Blum.pdf

BONOTTO, C., 2004, "How to Replace the Word Problems with activities of Realistic Mathematical Modelling", in Henn, W. \& Blum, W., eds, Proceedings of the ICMI Study 14: Applications and Modelling in Mathematics Education, University of Dortmund

BOWMAN, J., 1997, Making math relate to the real world. A math teacher challenges his students with interesting story problems. Retrieved September 12, 2004 from URL: http://www.4teachers.org/testimony/bowman/

BROOKES, D. W., 1994, The Nature of Conceptual learning and thinking. Unpublished article, University of Durban-Westville

DAVIS, P. J. \& HERSH, R., 1981, The Mathematical Experience, Boston: The Harvester Press

DE VILLIERS, M., 1993, "Modelling as a teaching strategy", Pythagoras 31, pp 3-4

DE VILLIERS, M., 1999, Rethinking Proof, Emeryville, USA: Key Curriculum Press
HODGSON, T., \& RILEY, K. J., 2001, "RealWorld Problems as Contexts for Proof", Mathematics Teacher 94(9), pp 724-728

KLAOUDATOS, N., \& PAPASTAVRIDIS, S., 2001, "Context orientated teaching", in Matos, J.F., Blum, W., Huston, S.K., Carreira, S.P., eds, Modelling and Mathematics education, Chichester: Horwood

MUDALY, V., 2004, The Role and Function of Sketchpad as a modelling tool in secondary schools. Unpublished doctoral thesis, University of KwaZulu-Natal

OLINICK, M., 1978, An Introduction to Mathematical Models in the Social and Life Sciences $\left(1^{\text {st }}\right.$ Edition), Addison-Wesley.

OLIVIER, A., MURRAY, H. \& HUMAN, P., 1992, "Problem-centred Learning: the case of division", Pythagoras 28, pp 33-36

SELDEN, A. \& SELDEN, J., 1999, Tertiary Mathematics Education research and its Future. A technical report number 1999-6 from the Tennessee Technological University. Retrieved October 15, 2003 from URL: www.math.tntech.edu/techreports/reports.html

VAN DEN HEUVEL-PANHUIZEN, M., 1998, Realistic Mathematics Education - work in progress. Retrieved August 19, 2004 from URL: www.fi.uu.nl/en/rme

ZULKARDI, 2003, How to design mathematics lessons based on the Realistic Approach? Retrieved October 17, 2003 from URL: www.geocities.com/ratuilma/rme.html

"The silence of infinite space terrifies me."

Pascal 